\title{
3. FLUID FLOW IN "VEIN STRUCTURES” IN PERU FOREARC BASINS: EVIDENCE FROM BACK-SCATTERED ELECTRON MICROSCOPE STUDIES ${ }^{1}$
}

\author{
Alan E. S. Kemp ${ }^{2}$
}

\begin{abstract}
"Vein structures" have been documented in several active margins (e.g., Japan Trench, Middle America Trench, North Barbados Ridge). Studies of the abundant veins recovered from depths as shallow as $8 \mathrm{~m}$ below the surface during Ocean Drilling Program Leg 112 (Peru) have shed new light on their development and significance. In the forearc basins of Peru, these structures occur in unconsolidated wet sediments as infill to en-echelon tension gashes, extensional microfaults, and broad discrete fissures. They generally have infill that is mesoscopically darker than the surrounding sediment and appears finer grained. These structures developed most intensely in laminated diatomaceous (opal-A) muds of the forearc basins and occur from depths of $8 \mathrm{~m}$ below the surface. Veins are most common at sites where faulting is observed on seismic-reflection profiles. Studies of the veins using back-scattered electron imagery (BSEI), energy dispersive analysis (EDA), and image analysis (IA) provide the first conclusive direct evidence of sediment dewatering from DSDP or ODP cores. This evidence includes (1) upward particulate mass transport, (2) subvertical realignment of particles, and (3) flushing of fine material into the veins. Porosity determination using IA indicates porosity reduction in the veins relative to the matrix of commonly more than $50 \%$. This contrast mainly results from a concentration of fine opal in these veins. Regularly spaced concentrations of fine material, identified in BSEI and termed here "ghost veins," do not affect sedimentary microfabrics. These ghost veins probably represent early stages of fluid segregation within the sediment and may be precursors to vein structures.
\end{abstract}

\section{INTRODUCTION}

The documentation and quantification of fluid flow and circulation in the ocean floor has emerged as a central theme in ocean drilling (COSOD II, 1987). Fluid flow in sediments from active margins has hitherto been generally inferred from geochemical data or direct observation at the sediment/water interface of mud volcanoes and unique biological communities with associated bathymetric and seismic surveys (e.g., Moore, Mascle, et al., 1987; Suess, von Huene, et al., 1988; Suess et al., 1986; Westbrook et al., 1983). Little documentation of microscopic evidence exists for fluid flow within sediments (papers in Moore, 1986). Clearly, a knowledge of the mesoscopic and microscopic mechanisms and effects of fluid motion in sediments is a critical prerequisite to any understanding of large-scale circulation processes. The aim of this study is to present the preliminary results of a backscattered electron imagery (BSEI) study of fluid flow within unconsolidated Peru forearc sediments and to show the way forward for future "ground-truthing" of fluid flow.

\section{VEIN STRUCTURES FROM THE PERU MARGIN}

Vein structures have been described from several active margins, and these occurrences have been reviewed in a companion paper (Lindsley-Griffin et al., this volume). During Leg 112, these structures, which generally take the form of subvertically oriented en-echelon tension gashes, extensional microfaults, and broader discrete fissures, were encountered most abundantly in unconsolidated sediments from PlioceneQuaternary upwelling sequences of the upper-slope and outershelf forearc basins (Lindsley-Griffin et al., this volume; Kemp and Lindsley-Griffin, this volume) (Fig 1). Preservation

\footnotetext{
${ }^{1}$ Suess, E., von Huene, R., et al., 1990. Proc. ODP, Sci. Results, 112: College Station, TX (Ocean Drilling Program).

2 Department of Oceanography, University of Southampton, Southampton SO9 $5 \mathrm{NH}$, United Kingdom.
}

of lamination in the anaerobic/dysaerobic upwelling sediments (Kemp, this volume) provides abundant marker horizons that aid recognition of vein structures. Within these forearc basins, veining is most intense at locations such as Site 679 where there was strong evidence from seismic profiles for normal faulting (Suess, von Huene, et al., 1988). Veining has been observed from depths as shallow as $8 \mathrm{~m}$ below the surface and may be common from depths of $10 \mathrm{~m}$ below the surface.

It should be emphasized that several of the vein structures described were not recognized during visual examination of core material. Many examples (such as those shown in PI. 1) were fortuitously observed in samples examined during study of primary sedimentary fabrics (Kemp, this volume).

\section{Methods}

Samples of core were impregnated with low-viscosity epoxy resin and finely polished. The techniques and instruments used are discussed in detail in a companion paper (Kemp, this volume). Interpretation of the BS images obtained from the Peru margin sediments is discussed in detail in Kemp (this volume) and by Kearsley in Patience et al. (this volume). A more general introduction to BSEI may be found in Pye and Krinsley (1984).

\section{MICROSCOPIC CLASSIFICATION OF VEINS}

From BSEI studies, veins may be characterized as those that obviously involve dilation and/or displacement across the vein (tension gashes and microfaults) and those that do not appear to affect the gross sediment structure (termed "ghost" veins). In back-scatter imagery, both types of veins always appear brighter than the surrounding matrix sediment, and thus their geometry is readily delineated. Microfault-veins occur both as isolated features (Pl. 1) and as anastomosing or subparallel networks (Pls. 2 and 3, respectively). In some cases, groups of thin (about $10 \mu \mathrm{m}$ ), subvertically oriented veins appear to form part of a regularly spaced planar fabric within the sediment (Pl. 4, Fig. 4). Locally, different types of 


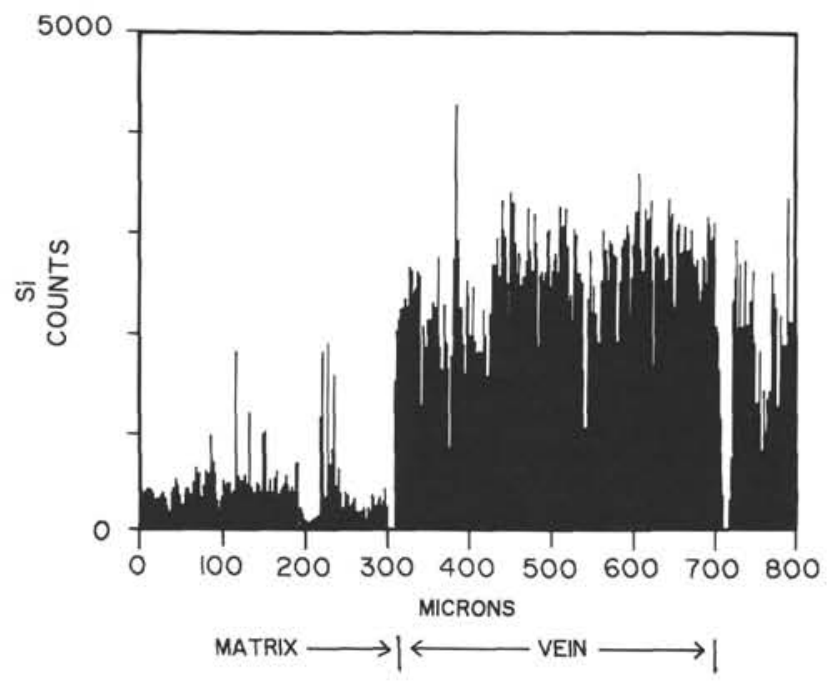

Figure 1. Trace of printout of energy dispersive X-ray microanalysis (EDA) traverse of silica in vein structure shown in Plate 4, Figure 1. Higher counts are from within the vein, confirming reduced porosity and presence of fine opaline silica within vein.

veins may be superimposed; for example, tension gashes may cut extensional microfaults ( $\mathrm{Pl}$. 3). This multigeneration veining is characteristic of zones of more intense veining at Site 679 and parts of Site 680.

\section{COMPOSITION OF VEINS}

A brighter back-scatter signal from vein interiors reflects a higher mean atomic number. Most of the contrast contained in the BS images of Plates 1 through 5 is due to variations in porosity, with the more porous areas (with high resin content) appearing dark and the less porous areas (with lower resin content) appearing brighter. Higher-resolution BSE imagery (Pl. 4) shows that the vein interiors have greater quantities of finer material than the surrounding matrix. This applies not only to microfault and tension-gash veins, but also to ghost veins (Pl. 5). Compositionally, this vein material is otherwise similar to that in the matrix, although increased calcium carbonate content has been locally recognized. Where veins cut diatom oozes or diatomaceous muds, fine opaline diatom fragments (such as setae) appear to be concentrated in the veins, and are relatively rarer in the matrix (Pl. 4), except in fecal pellets (Kemp, this volume). Thus, the veins have substantially lower porosity than the matrix (see below). ED line traverses across veins confirm the higher concentration of silica within the vein (PI. 4 and Fig. 1). A greater appreciation of vein composition must await more detailed compositional mapping of veins and matrix.

\section{EVIDENCE FOR FLUID FLOW IN VEIN STRUCTURES}

Vein structures exhibit a number of features that provide evidence for fluid flow. These include direct evidence, such as upward displacement of particles within veins from marker horizons as well as indirect evidence provided by the redistribution and concentration of fine material within the sediment. (Supporting evidence such as orientation of particles within veins has been noted previously.)

\section{Upward Mass Transport}

The most unequivocal evidence for upward passage of fluid in vein structures is the upward transport of material. This can best be observed where vein structures cut layers of marker grains, such as very fine sand/silt layers within diatomaceous mud (Pl. 1). Here, a thin laminae of silty-sand is cut by several veins, which are delineated by their brighter tone. Details (PI. 1, Figs. 2, 3) indicate that despite downthrow on the microfault associated with one of these veins, coarser grains from the marker lamina have been displaced upward. Evidence such as this has not previously been documented from either DSDP or ODP cruises, which may reflect the very limited amount of BSEI studies conducted. Some quantification of rates of fluid flow in sediment may be possible from examples such as that shown in PI. 1, where fine sand grains have been transported upward for a minimum of $0.5 \mathrm{~mm}$. Qualitatively, this example probably implies fairly rapid upward expulsion of fluid. It should be noted, however, that evidence such as this relies on the presence of a readily identifiable marker horizon and may be relatively rarely encountered.

\section{Orientation of Material Within Veins}

Elongate particles within isolated veins and extensional microfault vein networks are often oriented subvertically parallel to the vein walls (Pl. 4, Figs. 2 and 4), in contrast to a crude horizontal, bedding subparallel orientation in the surrounding matrix (PI. 4, Fig. 3). Much of the material reoriented within veins is composed of fine diatomaceous debris (Pl. 4, Fig. 2) but also includes clay (Pl. 4, Fig. 4). This orientation of material is consistent with upward fluid flow but also with reorientation during shearing along the vein (Arthur et al., 1980) or porosity collapse (Knipe, 1986); however, see discussion below.

\section{Segregation/Concentration of Fine-Grained Material}

A universal feature of all styles of veins is the concentration of fine-grained material within them relative to the surrounding matrix. This material substantially resembles that observed in the surrounding matrix, which is typically composed of fine diatomaceous fragments and very fine silt- and clay-grade terrigenous feldspathic silt and clay. Veins also include some volumetrically less significant material, such as carbonate and very fine amorphous silica, that may originate from dissolution/precipitation reactions in migrating pore fluids.

The porosity reduction within the veins relative to the local matrix has been quantified using image analysis of digitally acquired BSE images. While these values do not correspond to bulk porosity measurements, they do represent a local cross section of porosity perpendicular to bedding. Porosity values range from $20 \%$ to $50 \%$ in the matrix down to $10 \%$ to $20 \%$ in the veins, indicating porosity reduction of over $50 \%$. The presence of greater relative amounts of very fine material within veins implies some flushing of material from surrounding sediment, which could be accomplished by pore fluid migrating into the veins. It is difficult to envisage a mechanism not involving fluid flow for redistribution of fines.

\section{Significance of Ghost Veins}

Ghost veins occur in a range of geometries from more or less regularly spaced pillars (Pl. 5, Fig. 1) to interlocking meshworks (PI. 5, Fig. 3). These ghost veins contain higher concentrations of fine material and are less porous than the adjacent matrix. However, they are not associated with any other modification of pre-existing sediment fabrics, such as microfaulting or dilation, and are restricted in vertical extent. Plate 5, Figure 1, for example, shows a series of ghost veins in a finely laminated diatom ooze layer containing microlaminae of silt that show no disruption or modification within the ghost veins. Thus, there is no evidence for dilation or displacement during their formation. No preferred orientation of particles 
has thus far been observed in ghost veins. Ghost veins tend to occur preferentially in the more porous diatom ooze layers (Pl. 5), although they may continue into adjacent diatomaceous muds. Significantly, although ghost veins are most abundant at sites such as Site 679 , where other vein structures are most common, they tend to occur in zones of less intense veining, which lack microfault networks or broad discrete gashes.

Ghost veins probably result from some segregation of fluid that exploits existing porosity and permeability and is not associated with "failure" of the sediment. These ghost veins may have been zones of elevated pore fluid pressure, which promoted formation of dilational or displacive veins associated with bulk dewatering (see Fig. 2). The regularity of their spacing may represent some fundamental spacing associated with fluid segregation and/or local stress fields.

\section{DISCUSSION}

Note that the sediments or the Peruvian forearc basins are compositionally distinctive in their high diatom content relative to most other sequences drilled by ODP and DSDP. These diatomaceous sediments are distinguished by their anomalously high wet strengths (Hill and Masters, this volume), which may account for the early formation of the vein structures at depths of as little as $8 \mathrm{~m}$ below the surface in sediments of Pleistocene age. Nevertheless, the vein structures of the Peruvian forearc basins probably represent important analogs for other vein structures encountered in DSDP and ODP. Significantly, a relatively shallow occurrence of vein structures was noted by Cowan (1982) in Pleistocene sediments at depths of $150 \mathrm{~m}$ below the surface, also in unconsolidated diatomaceous muds.

Unlike previous examples encountered (during DSDP or ODP cruises), there is significant evidence for upward fluid migration (from upward mass transport) and fluid segregation (from the ghost veins) associated with vein structures from Peruvian forearc basins. A fluid flow mechanism for orientation of particles is supported by this evidence, although orientation of particles per se is consistent with, but does not prove, fluid flow. Some of the other mechanisms summarized in Knipe (1986) may also apply, but there is no evidence to support the "collapse mechanism" for causing orientation, as is required by the dilation-displacement-collapse model of Knipe (1986) or Ritger (1985).

The porosity reduction documented in the Peru vein structures might be expected to militate against fluid flow, but the decreased tortuosity (Arch and Maltman, in press) produced by particle alignment may compensate for this. More EDA compositional mapping will be required to characterize the dissolution/ precipitation reactions that are associated with fluid migration and to link microfabric analysis with studies of pore-water chemistry. Detailed compositional mapping may also provide evidence of fluid transport within veins. A possible model for formation of the vein structures is shown in Figure 2.

\section{IMPLICATIONS FOR VEIN DEVELOPMENT}

While it is accepted that a range of mechanisms may apply, the evidence presented above demonstrates that at least some of the Peru forearc veins were associated with rapid fluid expulsion (e.g., PI.1). This provides partial support for the "streaming" fluid mechanism (Cowan, 1982), which advocates reorientation of grains in response to water streaming through veins.

Study of ghost veins shows that significant fluid-driven segregation of fine material occurs prior to any dilation or microfaulting of the sediment. Indeed, the ghost veins may be
A

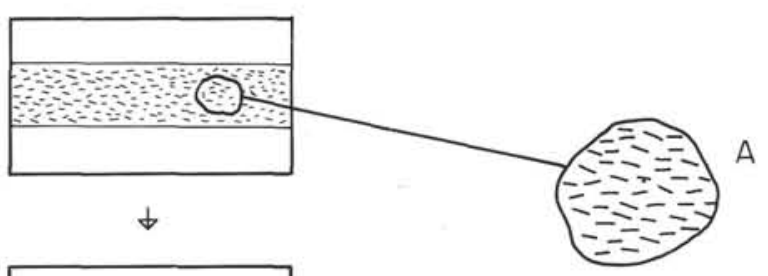

B

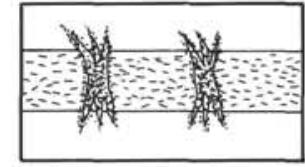

$\downarrow$

C

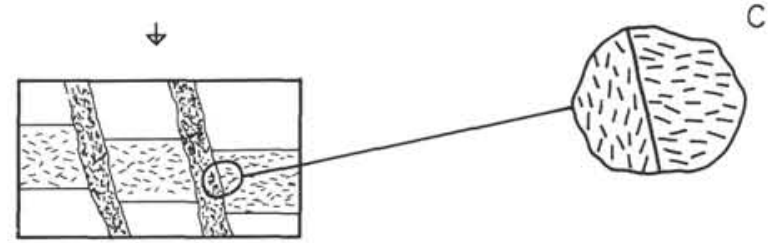

Figure 2. A possible model for the evolution of the vein structures. A. Original sediment configuration showing diatom ooze lamina within diatomaceous mud. Detail shows crude bedding-parallel orientation of elongate particles (including diatom frustules, see Pl. 4, Fig. 3). B. Formation of ghost veins preferentially in diatom ooze lamina by fluid-driven segregation of fines. Little sediment deformation or modification of microfabrics occurs at this stage. C. Displacive microfaults form preferentially at sites of ghost veins. Detail shows particles within veins are oriented by "streaming fluid" escaping upward in veins, as in Plate 4, Figure 2.

a hitherto unrecognized precursor forming the locus for development of dilational and/or displacive vein structures.

Scientists who have selectively studied vein structures in lithified sediments from deeper/older levels of forearcs have assumed that the structures that they describe were "produced in lithified sediments" (Knipe, 1986). The presence of abundant vein structures in unconsolidated muds of Pleistocene age from depths as shallow as $8 \mathrm{~m}$ below the surface suggests that the initiation of many veins may be at much shallower depths and in less consolidated sediment than hitherto supposed.

\section{ACKNOWLEDGMENTS}

This research and my participation in Leg 112 was funded by the Natural Environment Research Council. I am grateful to two anonymous reviewers for suggestions that led to the improvement of the manuscript.

\section{REFERENCES}

Arch, J., and Maltman, A. J., in press. Anistropy, permeability and tortuosity in deformed wet sediments. J. Geophys. Res.

Arthur, M. A., Carson, B., and von Huene, R., 1980. Initial tectonic deformation of hemipelagic sediment at the leading edge of the Japan convergent margin. In Lee, M., Sout, L., et al., Init. Repts. DSDP , 56, 57: Washington (U.S. Govt. Printing Office), 568-615.

COSOD II, 1987. Second Conf. Scientific Drilling (Strasbourg, France).

Cowan, D. S., 1982. Origin of "vein structure" in slope sediments on the inner slope of the Middle America Trench off Guatemala. In Aubouin, J., von Huene, R., et al., Init. Repts. DSDP, 67: Washington (U.S. Govt. Printing Office), 645-650.

Knipe, R. J., 1986. Microstructural evolution of vein arrays preserved in Deep Sea Drilling Project from the Japan Trench, Leg 57. Geol. Soc. Am. Mem., 166:75-87.

Moore, J. C. (Ed)., 1986. Structural Fabrics in Deep Sea Drilling Project Cores from Forearcs. Geol. Soc. Am. Mem., 166:1-160.

Moore, J. C., Mascle A., and Leg 110 Shipboard Scientists, 1987. Expulsion of fluids from depth along a subduction-zone decollement horizon. Nature, 326:785-788. 
Pye, K., and Krinsley, D. H., 1984. Petrographic examination of sedimentary rocks in the SEM using backscattered electron detectors. J. Sediment. Petrol., 54:877-888.

Ritger, S. D., 1985. Origin of vein structures in the slope deposits of modern accretionary wedges. Geology, 13:437-439.

Suess, E., Carson, B., Ritger, S., Moore, J. C., Kulm, L. D., and Cochrane, E. G., 1986. Biological communities at a vent site along the subduction zone off Oregon. Biol. Soc. Wash. Bull. 6:475-484.
Suess, E., von Huene, R., et al., 1988. Proc. ODP, Init. Repts., 112: College Station, TX (Ocean Drilling Program).

Westbrook, G. K., and Smith, M. J., 1983. Long décollements and mud volcanoes. Geology. 11:279-283.

Date of initial receipt: 14 January 1989

Date of acceptance: 3 August 1989

Ms 112B-134 


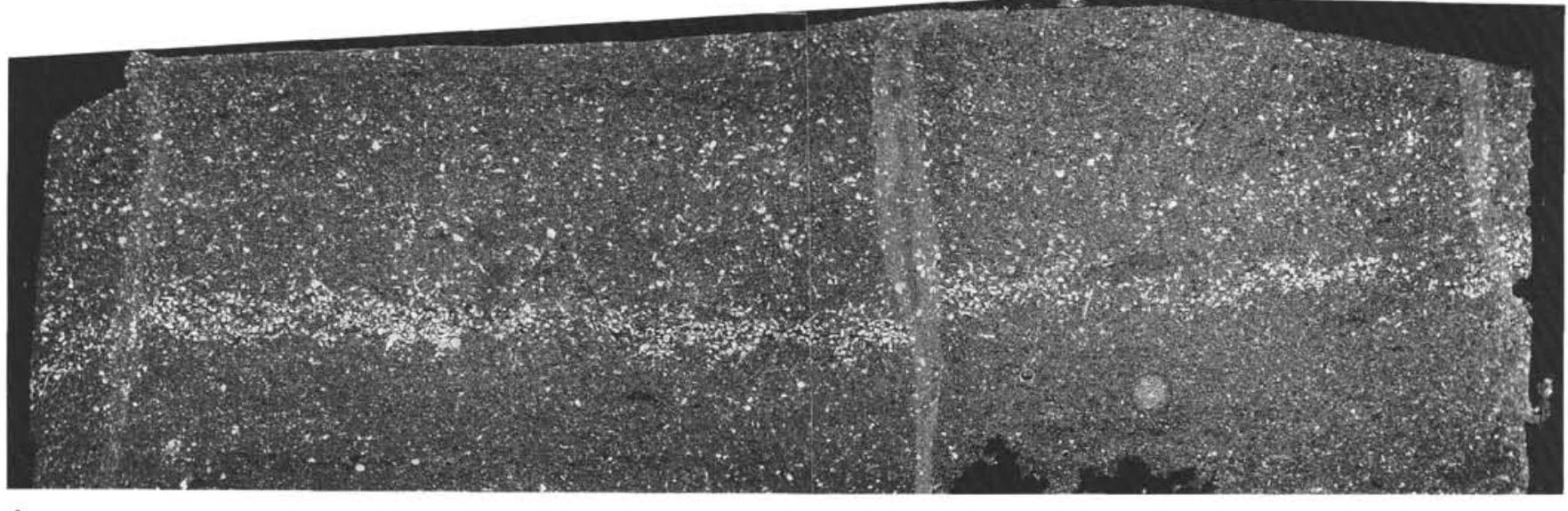

1
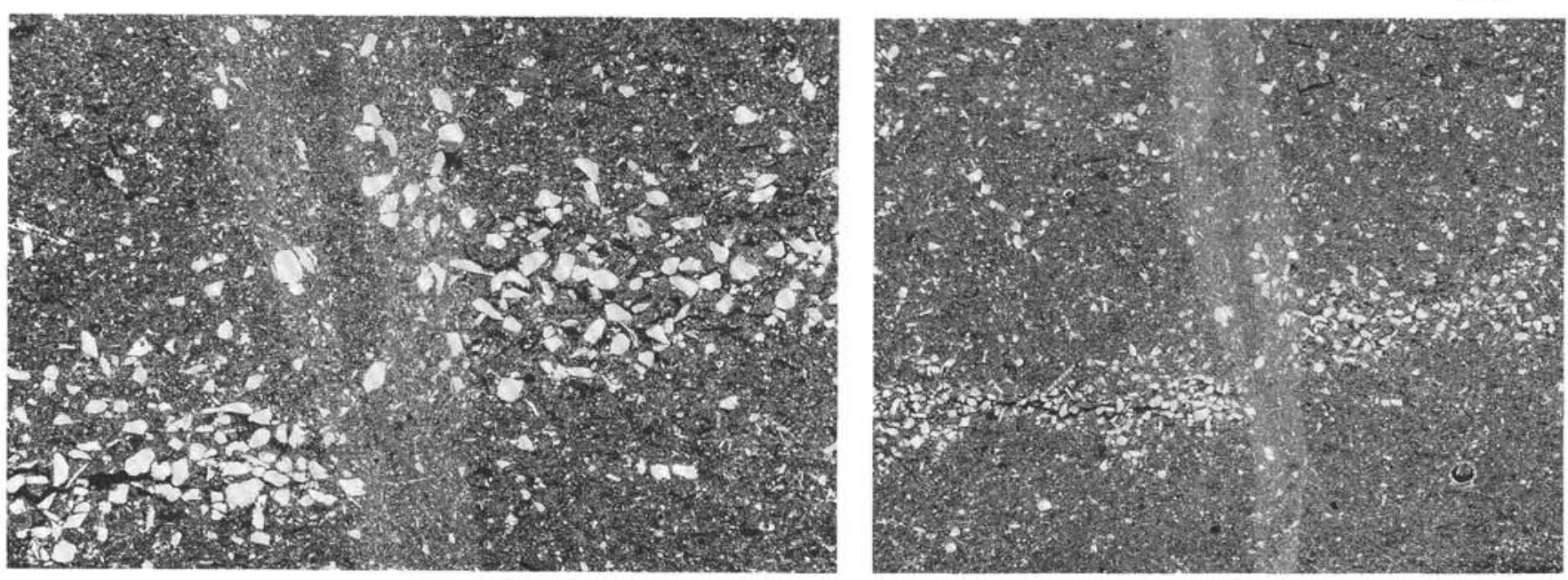

2

$100 \overline{\mu \mathrm{m}} \quad 3$

$1 \mathrm{~mm}$

Plate 1. BSEI of impregnated sediment showing evidence for upward motion of fluid in vein structures from Site 680 (112-680B-2H-5, 90-91 cm). 1. General view of fine/very fine sand and silt layer in silty diatomaceous mud cut by vein structures associated with minor faults and fluid escape features. 2, 3. Detail of bifurcating vein (mid-right, Fig. 1). Fine sand grains are transported upward a minimum of $5 \mathrm{~mm}$ in this vein, providing unequivocal evidence for upward mass transport related to upward fluid migration. 


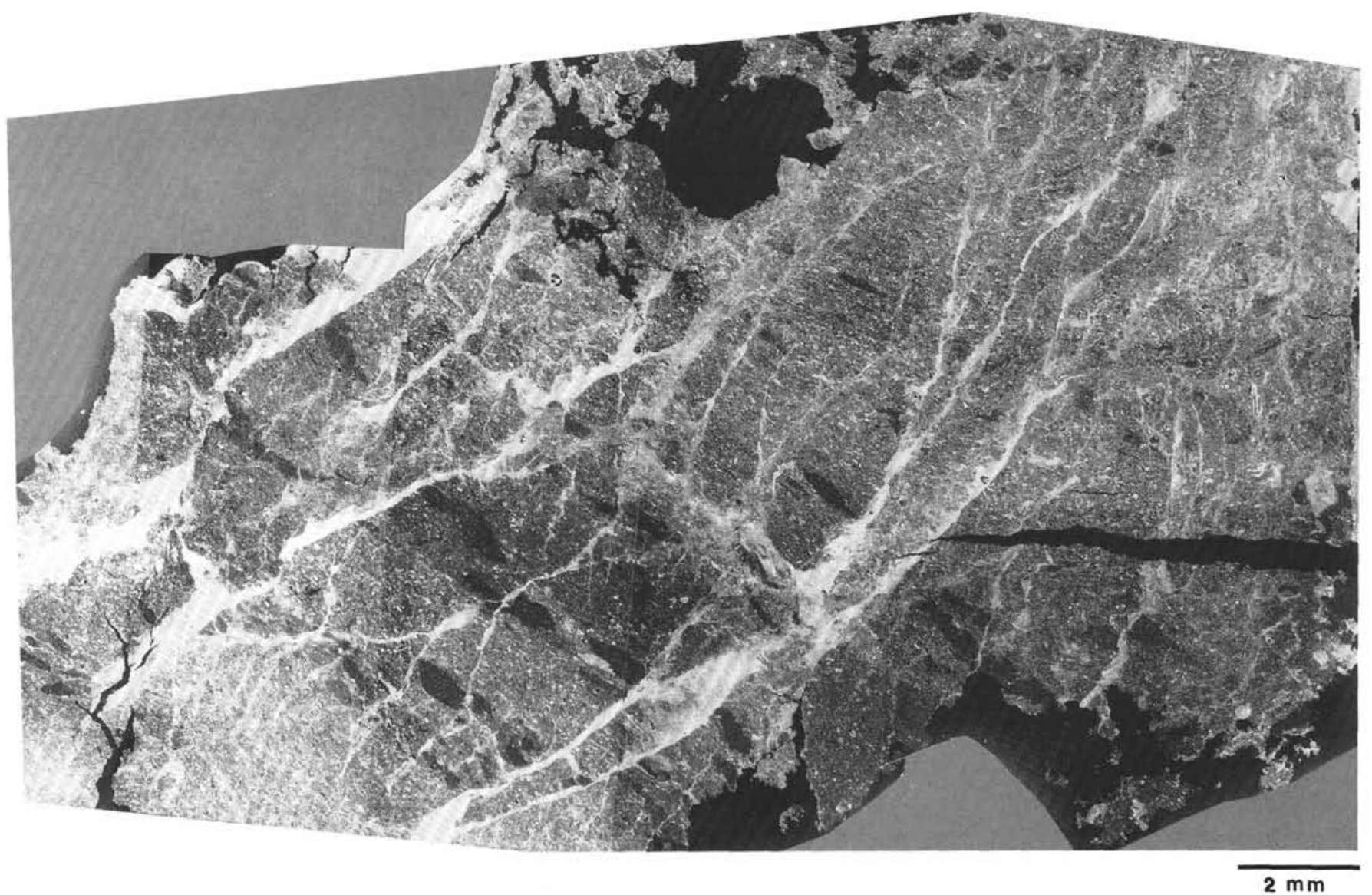

Plate 2. BSEI showing general view of anastomosing vein-filled microfaults that dissect interlaminated diatomaceous mud and ooze. (112-679D-7H-3, 80-82 cm). Dark oval structures are probably anchovy fecal pellets (see Kemp, this volume). Detailed analysis of the marked vein (center left) is shown in Plate 4. 


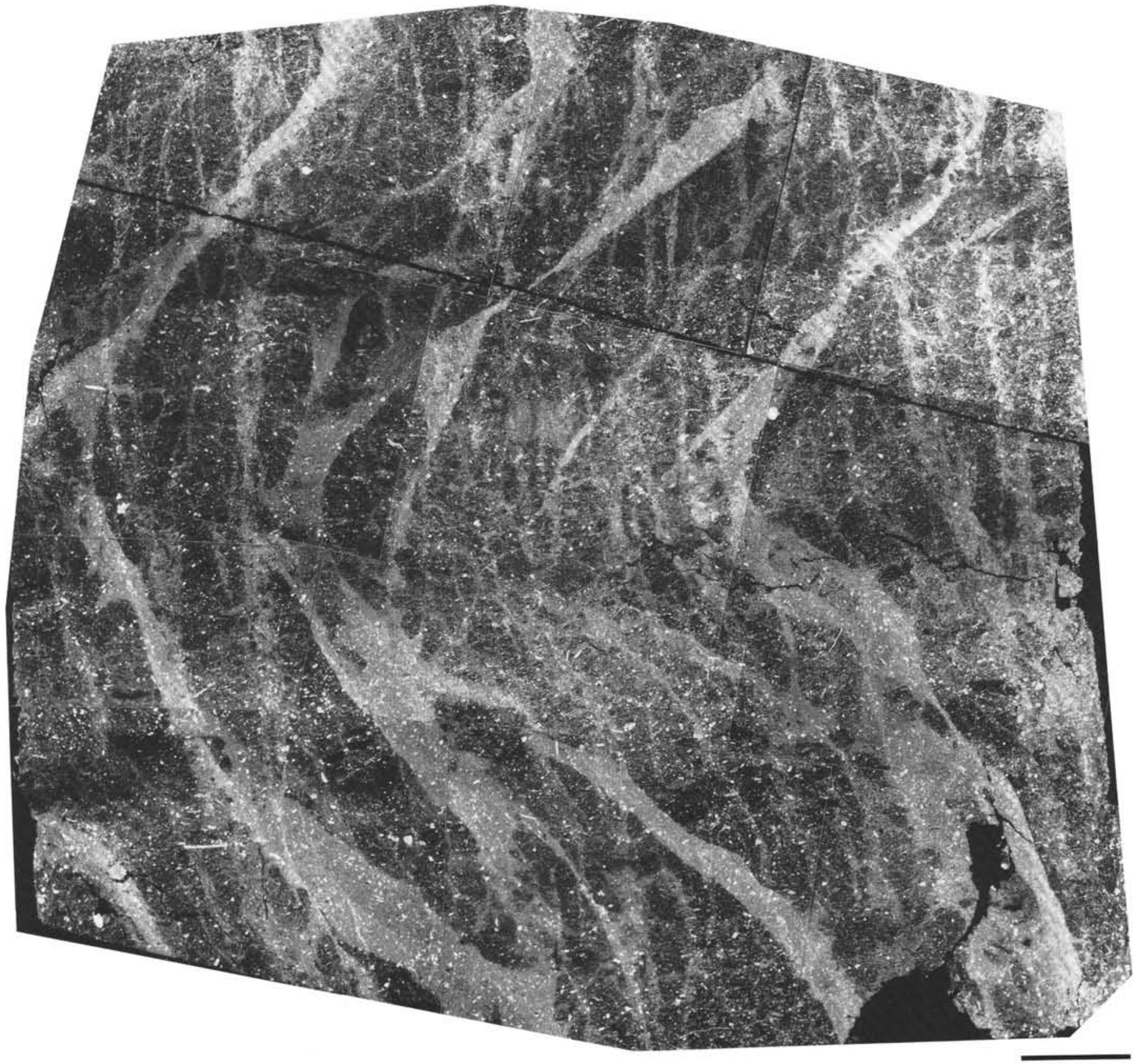

$2 \mathrm{~mm}$

Plate 3. BSEI showing at least two generations of veining of different styles in laminated diatomaceous mud (112-680B-7H-3, 18-20 cm). Darker layers are diatom ooze. An earlier subvertical vein set $(\mathrm{E})$, which is associated with minor microfaulting of laminae, is cut by a later thicker vein (L) set that takes the form of sigmoidal tensional openings. 

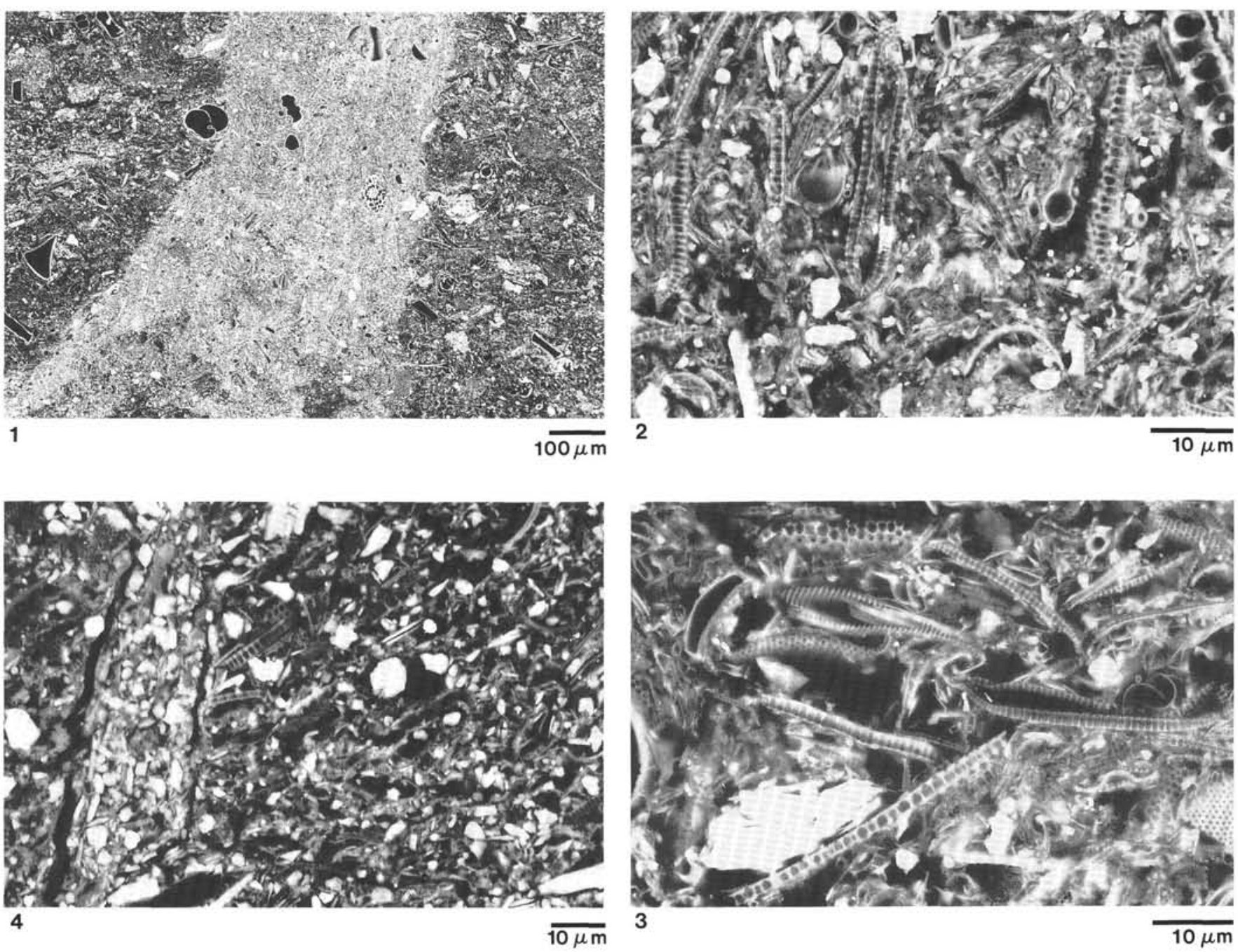

Plate 4. BSEI showing details of vein structures. 1. Detail of individual vein in Plate 2. Line marks locus of EDA traverse shown in Figure 1. Bedding is horizontal in this perspective. 2, 3. Interior of vein and matrix to vein, respectively. Note much greater abundance of fines and reduction of porosity within the vein relative to matrix. Elongate particles are oriented subvertically parallel to vein margins within the vein (2). In the matrix, elongate particles exhibit a crude bedding subparallel orientation (3). 4. Relatively thin vein that is part of a subvertical spaced planar fabric (112-686B-3H-2, $116 \mathrm{~cm})$. 


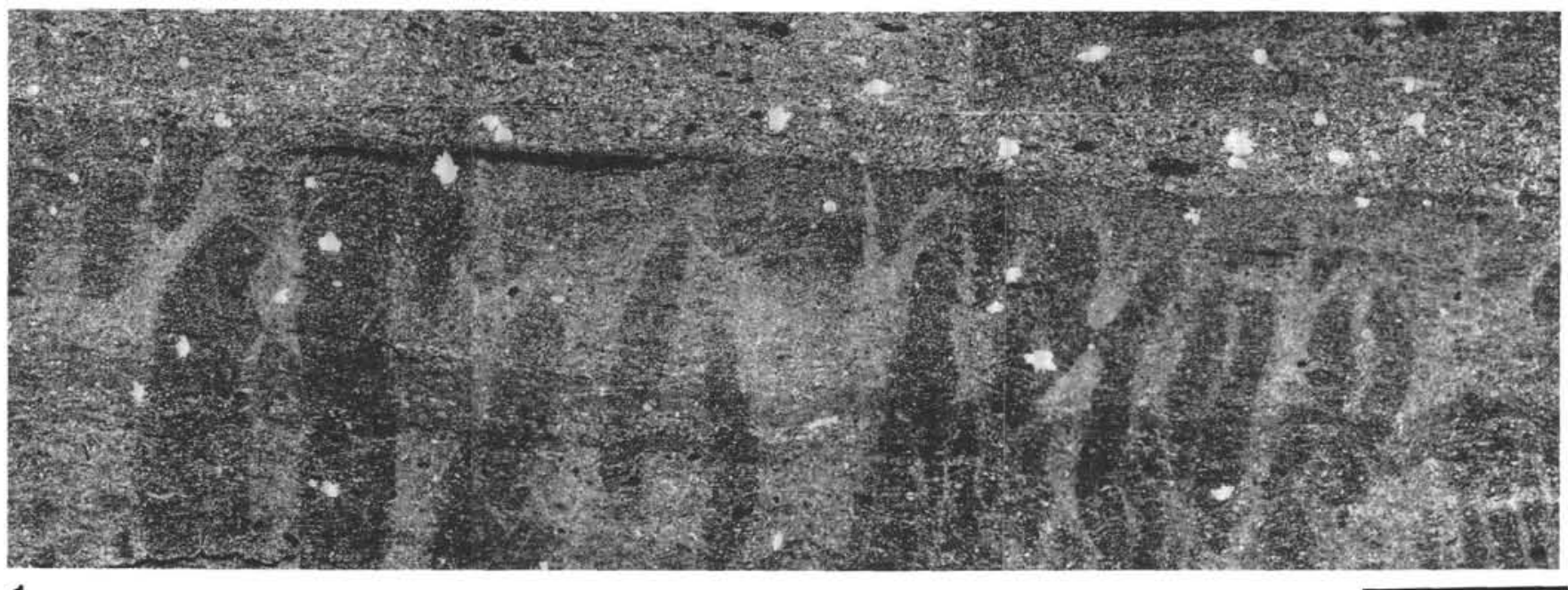

1

$2 \mathrm{~mm}$

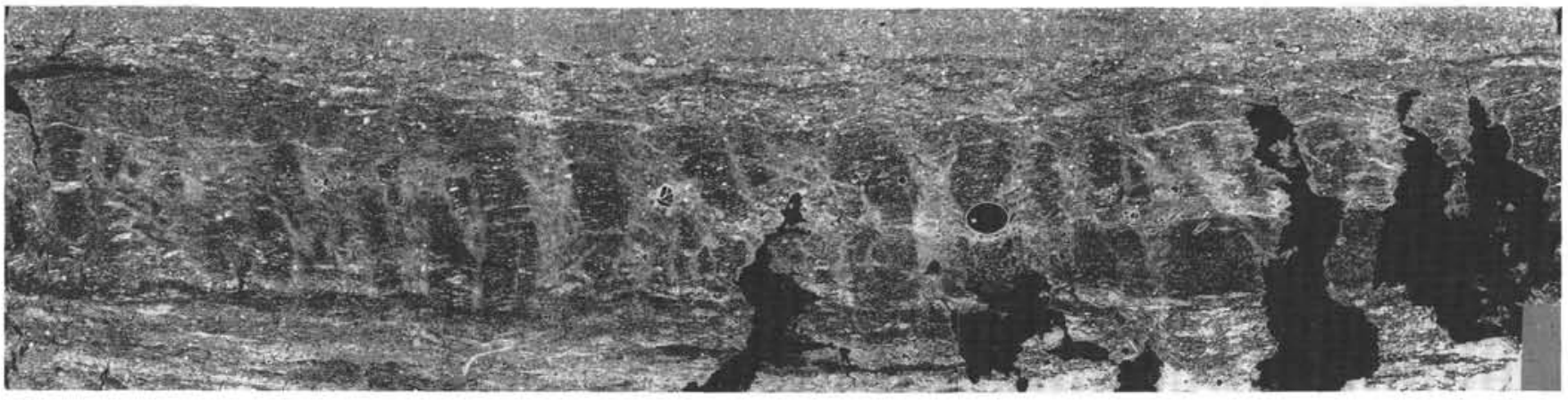

2

$2 \mathrm{~mm}$

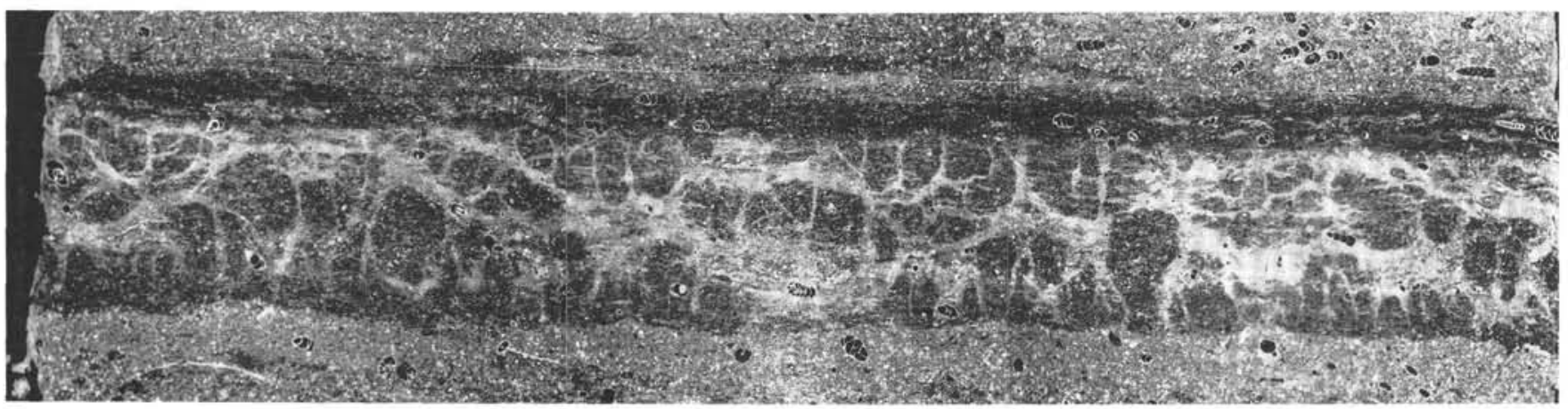

3

$2 \mathrm{~mm}$

Plate 5. BSEI of ghost veins developed preferentially in diatom ooze layers/laminae exhibiting a range of geometries from more or less regularly spaced pillars (Fig. 1) to interlocking meshworks (Fig. 2). These structures are not associated with displacive deformation of primary layering in the ooze layers. The higher back-scatter signal is from the presence of more very fine material within the veins than elsewhere. Much of this fine material appears to be very fine opal. Individual vein strands may have semiregular spacing. Veins appear thickest in the center of ooze layers and bifurcate to thinner strands or tributaries toward the vein margins. 1. Sample 112-680B-10H-5, 51-52 cm. 2. Sample 112-687B-3H-4, 51-53 cm. 3. Sample 112-687B-6H-3, 107-109 cm. 